\title{
El texto en escena: operaciones en la puesta de GAS/GAZ de Tom Lanoye
}

\section{( Catalina Cepernic}

Facultad de Filosofía y Humanidades/Facultad de Lenguas - Universidad Nacional de Córdoba, Argentina

catacepernic@gmail.com

Fecha de recepción: 29/3/2021. Fecha de aceptación: 18/05/2021

\section{Resumen}

Este artículo tiene como objetivo observar las operaciones en la escena que convierten a GAS/GAZ Alegato de una madre condenada en una obra inespecífica y, particularmente, de qué forma el texto opera de manera autónoma y se configura como objeto de exposición en la puesta. GAS/GAZ es una obra escrita por Tom Lanoye, dramaturgo belga, y se trata de un monólogo en el que la madre del responsable de un atentado terrorista lleva a cabo una suerte de alegato en defensa tanto propia como de su hijo. La traducción al español de esta obra fue realizada por Micaela van Muylem y llevada a escena por la Compañía Teatro Magdalena (Santiago de Chile) en 2017.

Palabras clave: inespecificidad, objeto de exposición, texto dramático, escena posdramática, poliglosia, GAS/GAZ, Lanoye

\section{Text on stage: operations in the staging of GAZ by Tom Lanoye}

\begin{abstract}
The aim of this article is to observe the onstage operations that make GAZ: Pleidooi van een gedoemde moeder an unspecific piece, and particularly, in which manner the text operates autonomously and becomes an object of exposition in the representation. GAZ: Pleidooi van een gedoemde moeder is a play written by Tom Lanoye, belgian dramatist, and consists of a monologue in which the mother of a man responsible for a terrorist attack carries out a sort of plea in self-defense but also in defense of her son. The play was translated to Spanish by Micaela van Muylem and enacted by Compañía Teatro Magdalena (Santiago de Chile) in 2017.
\end{abstract}

Keywords: unspecificity, object of exposition, dramatic text, postdramatic scene, polyglossia, GAS/GAZ, Lanoye 


\section{Inespecificidad y tangibilidad}

En la puesta en escena de $G A S / G A Z$ se producen numerosos desplazamientos y entran en juego múltiples lenguajes que se superponen y dialogan entre sí: texto, movimiento, música, proyecciones, elementos de la escenografía (fig. 1). Es por esto que podemos pensar que se trata de una obra inespecifica, siguiendo la definición de Florencia Garramuño. En su Mundos en común: Ensayos sobre la inespecificidad en el arte, la autora hace referencia a "la proliferación cada vez más insistente de cruces de soportes y de materiales, que aparece como una suerte de condición de posibilidad -de horizonte, diría- de la producción de las prácticas artísticas contemporáneas." (Garramuño, 2015:26). El carácter inespecífico de esta obra se evidencia, en principio, en la definición de su género: en su edición en papel, en neerlandés, se define y se distribuye como nouvelle (o "novela corta"); sin embargo, fue llevada a la escena, y escrita para la escena. Por otra parte, al interior de la puesta, su inespecificidad o porosidad tienen que ver con los cruces y desplazamientos que se dan entre los distintos lenguajes en escena. La autora también plantea que, en el arte inespecífico, se lleva a cabo “...toda una exploración de la sensibilidad en la que nociones de pertenencia, individualidad y especificidad son continuamente desplazadas." (Garramuño, 2015: 13). Volveremos más adelante sobre esta última idea.

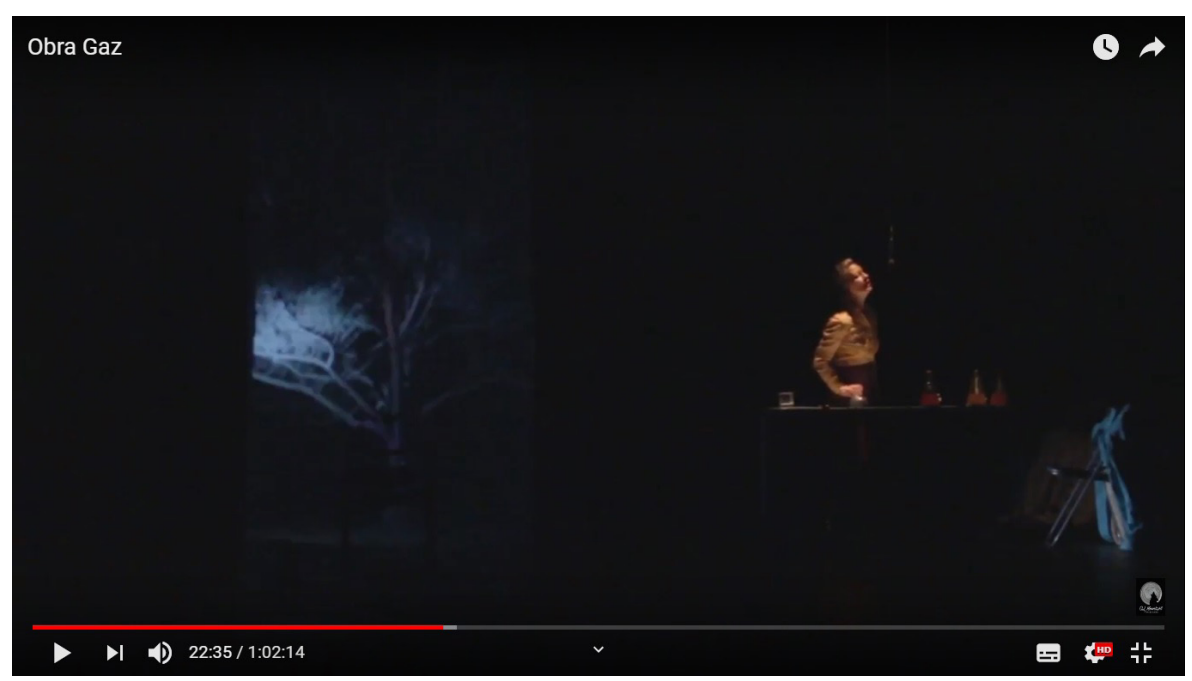

Figura 1. Captura de pantalla del registro de la puesta en escena de GAS/GAZ (gentileza de la compañía Magdalena).

De todos esos desplazamientos y cruces de fronteras, nos proponemos observar particularmente los que se dan en relación con el elemento textual. En primer lugar, presentaremos las nociones a utilizar para llevar a cabo el análisis. En su artículo "El texto como objeto. Sobre la autonomía recuperada del texto dramático", el investigador flamenco Ronald Geerts plantea que el texto dramático se configura como un elemento autónomo $y$ como un objeto en dramaturgias europeas contemporáneas, y realiza un análisis de las diferentes maneras en las que esta operación se lleva a cabo. El autor afirma que en el teatro posdramático se da una operación dual con respecto al texto: mientras que este sufre una "pérdida de autoridad", a su vez aparece frecuentemente como un objeto en la escena. Geerts sostiene que en el teatro posdramático el texto es solo uno de los tantos componentes que conforman la obra como un todo y que no posee una "superioridad", propia de la jerarquía del teatro tradicional. Sin embargo, observa que 


\begin{abstract}
el texto se manifiesta en el teatro posdramático cada vez más como un lenguaje "tangible", como palabra e incluso como objeto textual. Sus formas materiales más que nunca enfatizan su carácter textual y aumentan sin duda su autonomía con respecto a los demás símbolos teatrales (2011:106) [La traducción al español de este texto está incluida en el presente dossier.]
\end{abstract}

El investigador recoge la noción de "texto como objeto" del teórico alemán HansThies Lehmann. Este, en su libro Teatro posdramático, plantea que en la puesta teatral el lenguaje se convierte en un objeto de exposición: "el lenguaje pierde su orientación al sentido y su temporalidad teleológica inmanentes, y deviene equiparable a un objeto expuesto" (2013:260).

Por último, trabajaremos a partir de la noción bajtiniana de heteroglosia a la que también refiere Geerts en el texto citado. El autor afirma que "en el carácter heteroglósico de una representación teatral, el uso de diferentes lengua(je)s hace emerger formas dialógicas de comunicación. El diálogo se desarrolla entre las distintas lenguas en escena, pero también entre escena y público" (2011: 108).

A continuación, realizaremos un recorrido por las distintas maneras en las que el texto aparece en $G A S / G A Z$ de manera autónoma y se configura como objeto de exposición en la puesta en escena de la Compañía Teatro Magdalena, de Santiago de Chile. Para el presente trabajo consultamos el registro de la representación de la obra en dicha ciudad en el año 2017, cedido por la compañía, asimismo, tendremos en cuenta la puesta a la que asistimos en Córdoba el día 3 de noviembre de 2017, en la Sala menor, Ciudad de las Artes (Universidad Provincial de Córdoba).

\title{
Operaciones de extrañamiento
}

En primer lugar, la puesta comienza y finaliza con la actriz leyendo el guion en voz alta dentro de la escena. En el fragmento de apertura, lee el setting (fig. 2), que en la obra original está ubicado por fuera del monólogo, como cualquier didascalia. Luego de leer este fragmento completo, la actriz deja el guion a un lado para dedicarse a interpretar el monólogo propiamente dicho. En este primer momento, ya encontramos un extrañamiento con respecto a la escena y un desplazamiento del foco hacia el elemento textual. Esto se produce por dos motivos: el primero, la introducción del guion escrito en escena, y el segundo, la introducción del setting, elemento textual que, en principio, no es planteado para ser llevado a ella. Hacia el final de la obra, la actriz vuelve a tomar el guion para leer en voz alta, pero esta vez se trata de un fragmento del monólogo, más precisamente el último (de un texto que está dividido en secciones por blancos tipográficos).

El primero de estos momentos, la escena en la que la actriz lee el setting de la obra, se corresponde con la figura que Laura Fobbio denomina "monologante dramatúrgico". Se trata de una figura "fundamentalmente reflexiva y metaficcional, ya que ordena, parece regir el devenir del relato-acción, y metacomunica, es decir, se comunica acerca de la interacción que constituye la obra" (Fobbio, 2016: 60). En el caso de la obra de Lanoye, en la puesta en página, el único fragmento ajeno al monólogo propiamente dicho, a la voz del personaje, es el setting. Es decir que esta única sección que ordena la acción en la escena es llevada a ella en ese momento inicial en que la actriz la lee directamente desde el guion, introduciendo así la figura del monologante dramatúrgico en la obra. Este elemento siempre "se sitúa "entre" la obra y el lectorespectador..." (Fobbio, 2016:60). Lo interesante en este caso es que esta figura no se construye específicamente como une narradorx o locutorx, como es lo frecuente, sino que quien lo lee es la misma actriz que inmediatamente después recitará el resto de la 
obra. El único umbral entre el fin de la lectura del setting y el comienzo del monólogo se define por un cambio en el vestuario y la posición de la actriz, pero eso mismo sucederá posteriormente en otros momentos de la puesta y no indican cambios en la voz monologante.

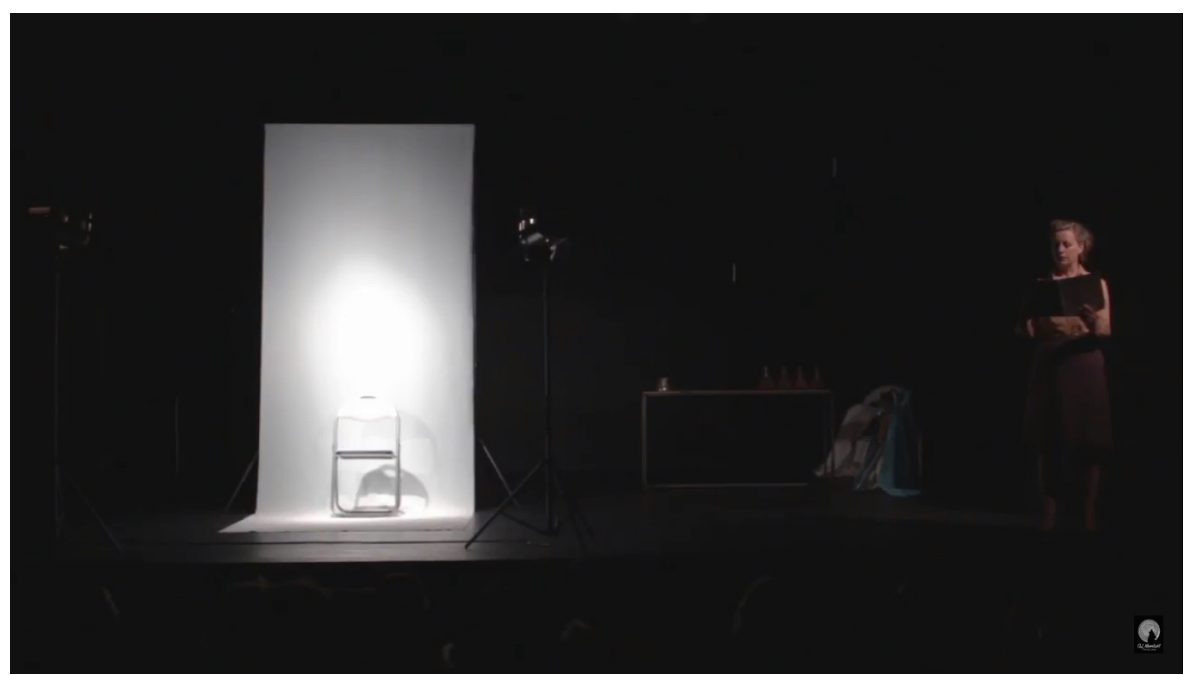

Figura 2. Captura de pantalla del registro de la puesta en escena de GAS/GAZ (gentileza de la compañía Magdalena).

Por otra parte, es propio de esta figura ubicarse en una tensión entre lo teatral y lo narrativo. En el caso de $G A S / G A Z$, el setting no necesariamente está pensado para ser representado: "Una mujer, al caer la tarde, en algún rincón de Europa Occidental. ... se acerca caminando con dificultad por un campo arado. ... Por encima de ella: un cúmulo de nubes ... una ciudad que se va encendiendo poco a poco..." (Lanoye, 2017: 128). Se trata de un relato muy detallado que sitúa a les lectores/espectadores, más que de una indicación para la escena, y esto nos recuerda al otro género con el que se define a esta obra: nouvelle. El setting, este texto inicial entre lo teatral y lo narrativo, es trasladado a la puesta y leído por un cuerpo dicente que se ubica "entre" personaje y narrador, en una escena que se ubica entre el monólogo y lo que está por fuera de él. Una vez más, nos encontramos frente al arte inespecifico del que habla Garramuño, y frente a una obra que puede ser leída como nouvelle o presenciada como monólogo.

Un último elemento a destacar en esta operación de lectura del guion en escena es la diferencia que mencionamos unas líneas más arriba: al final de la obra, la actriz vuelve a leer desde el papel, pero esta vez sí se trata de un fragmento del monólogo propiamente dicho. Es decir, la puesta comienza con la figura de monologante dramatúrgico; y finaliza volviendo a ubicar el foco en el guion, en el texto dramático, en el lenguaje como objeto de exposición, pero esta vez se trata del personaje propiamente dicho, que lee sus líneas en escena.

Otra manera en que el texto se manifiesta como objeto de exposición es el momento en el que la actriz canta una canción infantil en su lengua materna. A lo largo de toda la obra es posible reconocer el acento extranjero de la actriz, de origen rumano-alemán. Esto no es un dato menor: implica desde el inicio un extrañamiento para les espectadores, que identifican que el castellano no es la lengua materna de la intérprete, hecho que cumple un rol fundamental en la construcción del personaje. Además del acento fácilmente identificable, nos encontramos con una escena puntual en la que la actriz canta y lo hace en alemán. Otra vez se produce un extrañamiento: ya sea que les espectadores dominen la lengua alemana o no, el intercambio de idiomas es una operación 
que no pasa desapercibida. En el caso de les espectadores que no comprendan la lengua alemana, es evidente que el extrañamiento no solo se da en la identificación de esa operación sino también en la no comprensión de lo que se canta. Sin embargo, a través de la melodía elegida es posible identificar que se trata de una canción infantil.

En otra de las escenas, la actriz recita un fragmento mencionando también la puntuación presente en el texto escrito: "Los disparos le habían arrancado una pierna/ coma/ que estaba puesta al lado de la otra/ coma/ como un extraño elemento de utilería/ punto/ a la mano izquierda le faltaban algunos dedos/ coma/..." (transcripción del registro cedido por la compañía). Una vez más, nos encontramos ante un extrañamiento para les espectadores o, mejor dicho, una puesta en foco sobre el lenguaje y sus elementos textuales, materiales, visuales. La materialidad del texto dramático y sus elementos visuales se introducen en la escena de manera audible. El fragmento constituye la descripción del estado del cuerpo del hijo de la protagonista luego de haberse realizado una autopsia: "Le habían abierto y vuelto a cerrar el torso." (Lanoye, 2017:149). Por otra parte, a la vez que enuncia el texto, la actriz muestra en sus manos un estudio radiológico; aparentemente, imágenes de un cerebro humano (fig. 3). En este sentido, hay un cruce tanto con el discurso médico como con el discurso forense; además de la presencia de la materialidad textual que ya mencionamos. Es decir, el desplazamiento hacia el texto como un objeto de exposición se da en este diálogo múltiple: lenguaje escrito y lenguaje oral; discurso forense/médico/anatómico y discurso dramático.

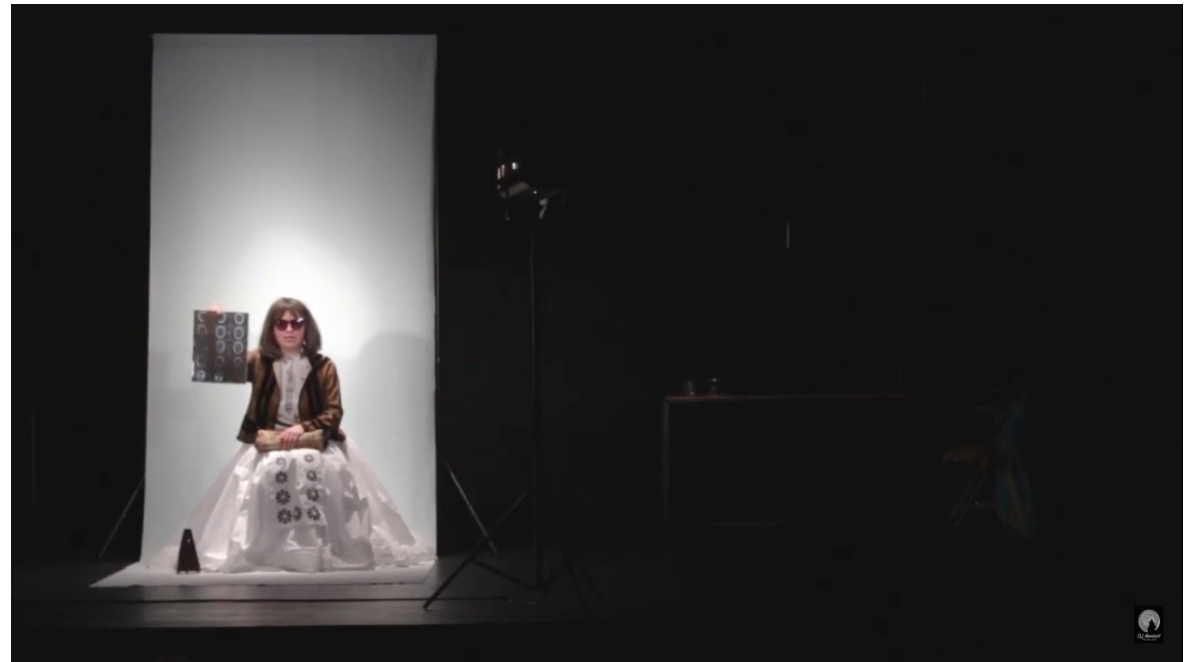

Figura 3. Captura de pantalla del registro de la puesta en escena de GAS/GAZ (gentileza de la Companía Magdalena).

\section{Doble operación}

Observemos ahora qué sucede con la pérdida de autonomía del texto de la que habla Geerts. El autor plantea que en la tradición posdramática, la puesta en escena funciona como suplemento del texto, ya no como su ilustración ni consumación. En este sentido, afirma que "desde el punto de vista de la representación como suplemento, aquella establece un diálogo con el texto. Esto concuerda con la idea posdramática de que el texto es solo uno de muchos elementos en un todo mayor y que pierde su estatus superior dentro de la jerarquía del teatro." $(2011,108)$. Si tomamos el registro de la representación de $G A S / G A Z$ de la compañía Teatro Magdalena y lo comparamos con el monólogo escrito, se evidencia un trabajo con el texto que da cuenta de esta nojerarquía. Las operaciones y los juegos presentes en la puesta son múltiples. Ya hemos mencionado algunos de ellos: la presencia del setting en escena, por ejemplo, ya que se 
trata de un fragmento que -se supone-no fue pensado para ser leído en ella, o al menos no hay ningún elemento textual que lo indique. Por otro lado, existen párrafos enteros del monólogo que no son enunciados por la actriz, además de la escena ya referida en la que los signos de puntuación del texto son dichos en voz alta. En todo momento, se trata de decisiones conscientes en la producción y dirección de la puesta. El texto no es tomado como el material a partir del cual la obra debe ser representada, sino que se trata de un elemento más con el que se puede jugar y trabajar en la escena.

Esta pérdida de autoridad, o esta horizontalidad jerárquica del texto con respecto a los demás lenguajes de la representación teatral, es evidente también en su superposición o fusión con ellos. A lo largo de la obra nos encontramos frente a escenas en las que todo sucede a la vez: una proyección visual, movimientos de la actriz, música, cambios en el canal de la voz (aire-micrófono), otros sonidos. Inclusive, hay momentos en que la actriz ni siquiera habla, sino que produce sonidos con copas o con el arco de un violín.

Es decir, entonces, que a la vez que el lenguaje se vuelve un objeto tangible en escena, por otro lado, el texto dramático pierde su autoridad y se vuelve un elemento que puede ser modificado, fusionado, eliminado, expuesto.

\section{Poli-heteroglosia}

La puesta en escena que analizamos en esta oportunidad constituye indudablemente un escenario heteroglósico. El texto fuente está escrito en flamenco (neerlandés), la traducción fue realizada al español rioplatense, la compañía es chilena y la actriz es una rumano-alemana residente en Chile. Ya hemos mencionado algunos elementos en los que esto se evidencia en la obra: el acento de la actriz y la canción infantil que ella canta. Por otra parte, si comparamos el texto editado con el monólogo llevado a escena, encontramos que algunas de las modificaciones que se llevan a cabo tienen que ver con la variante del español: la actriz elige traducir ciertos términos, y por supuesto, conjugaciones verbales, a la variante que le es propia.

Sin embargo, la heteroglosia propia de GAS/GAZ no se agota en el aspecto lingüístico: como hemos visto, la puesta en escena establece diálogos y superposiciones entre diferentes lenguajes que se hacen presentes. Sonido, imagen, movimiento, lengua y espacio tienen su lugar, su tiempo y su protagonismo a lo largo de la presentación; la presencia de todos estos lenguajes y los cruces que se dan entre ellos dan cuenta de una poliglosia constante que define la obra junto con la heteroglosia lingüística que ya mencionamos: "en el carácter heteroglósico de una representación teatral, el uso de diferentes lengua(je)s hace emerger formas dialógicas de comunicación. [A su vez] el diálogo se desarrolla entre las distintas lenguas en escena, pero también entre escena y público." (Geerts, 2011: 108).

Nos encontramos entonces frente a operaciones de extrañamiento con respecto a la lengua, una exposición de lo textual, y al mismo tiempo, frente a múltiples diálogos entre los diferentes lenguajes. Estos procedimientos, propios de la escena posdramática, constituyen formas de "exploración de la sensibilidad" (Garramuño, 2015). GAS/GAZ propone una puesta en crisis constante de los límites y jerarquías entre lo textual, lo sonoro y lo visual.

\section{Sobre el potencial político}

En el prefacio a Mundos en común, y en los análisis que desarrolla a lo largo del libro, Garramuño propone una lectura del potencial político del arte inespecífico: 
¿sería posible pensar que el potencial político de estas obras está ... en la manera en que ellas colocan en crisis sus propios materiales y una definición formalista de la estética como modo de apuntar hacia la transitividad de la obra en tanto apelación a un otro? Una respuesta posible a estas preguntas puede elaborarse a partir de cómo algunas de estas prácticas ponen en circulación afectos y sentimientos, tendiendo lazos y puentes entre comunidades transregionales y nómadas que permiten elaborar una definición novedosa y en tránsito de lo latinoamericano (2015:14).

Si bien esta propuesta abarca obras latinoamericanas, porque es el campo analizado y trabajado por Garramuño, nos gustaría trasladar esta propuesta a la obra de Lanoye. En el apartado anterior mencionamos la poliglosia que se da en escena, no solamente entre lenguas, sino también entre lenguajes artísticos. En el texto citado de Ronald Geerts, este autor habla del carácter social y político de la poliglosia en la puesta y su papel en la recepción de una obra (2011:108). Se trata de un recurso frecuente en el teatro contemporáneo:

... una manera de dar cuenta de la compleja identidad que se presenta en Flandes y que es abordada también por numerosos artistas, escritores y teatristas contemporáneos para dar cuenta no tanto de una experiencia individual, la del novelista, sino colectiva, de la compañía teatral, de la ciudad en que viven, del país (van Muylem, 2016: 142).

Esto, como hemos mencionado, está presente en la escena de GAS/GAZ y en toda su producción (texto flamenco, traducción rioplatense, actriz alemana, compañía chilena). Es interesante leer la poliglosia en esta obra de esa manera, como representación de una experiencia colectiva, por fuera de la escena. Por otro lado, es importante tener en cuenta el motivo de este monólogo:

La obra GAZ. Pleidooi van een gedoemde moeder fue escrita por encargo de GoneWest - Reflections on the Great War (Brujas). El punto de partida fue la conmemoración del primer ataque con gas en la historia de la humanidad, durante la Primera Guerra Mundial, conocida en Bélgica como “La gran guerra” (Lanoye, 2017:156).

Esta obra, entonces, tiene desde su redacción un evidente carácter político y social, teniendo en cuenta la conmemoración que da lugar a su encargo y también el suceso que narra: ataques de ese estilo son eventos frecuentes en la Europa contemporánea. Más allá de esto, nos parece interesante, a partir de los diálogos y desplazamientos que se dan en escena, pensar a la obra, tanto el texto como la puesta, como una de estas prácticas estéticas contemporáneas que Garramuño menciona, cuya riqueza radica en su potencial político, su propuesta de "discusión sobre las maneras de habitar el mundo" (2015: 14) y su aporte a "una redefinición de la estética en tanto fundamento de una relación ética: una relación con el otro y, por lo tanto, con el mundo." (2015:14). 


\section{Q Bibliografía}

" Fobbio, L. (2016). “Monologar desde el 'entre”" en van Muylem, M. (comp.). Paisajes dramatúrgicos: ensayos de teatro comparado. (pp. 49-78). Córdoba: Editorial de la Facultad de Filosofía y Humanidades, Universidad Nacional de Córdoba.

» Garramuño, F. (2015). Mundos en común, Buenos Aires: Fondo de Cultura Económica.

» Geerts, R. (2011). "Tekst als object. Over de herwonnen autonomie van de dramatekst" en Swyzen, C. y Vanhoutte, K. (ed.) Het statuut van de tekst in het postdramatische theater. (pp. 105-114). Amberes: ASP Editions, UPA.

"Lanoye, T. (2017). “GAS/GAZ Alegato de una madre condenada” en: Monólogos, páginas, escenas: dramaturgias de Latinoamérica y Europa. (pp. 127-157). Córdoba: Editorial de la Facultad de Filosofía y Humanidades, Universidad Nacional de Córdoba. Trad. Micaela van Muylem.

»Lehmann, H. T. (2013). “Texto” en Teatro Posdramático. (pp. 255-275). Trad. de Diana González. Ciudad de México: Paso de Gato.

"van Muylem, M. (2016). "La traducción como descentramiento" en van Muylem, M. (comp.). Paisajes dramatúrgicos: ensayos de teatro comparado. (pp. 135154). Córdoba: Editorial de la Facultad de Filosofía y Humanidades, Universidad Nacional de Córdoba. 